\title{
Interaction of Cobalt(II) Tetraarylporphyrins with an Ag(111) Surface Studied With Photoelectron Spectroscopy
}

\author{
— Supporting Information - \\ Thomas Lukasczyk, Ken Flechtner, Lindsay R. Merte, Norbert Jux ${ }^{\dagger}$, Florian Maier, \\ J. Michael Gottfried*, and Hans-Peter Steinrück
Universität Erlangen-Nürnberg, Lehrstuhl für Physikalische Chemie II, Egerlandstr. 3, 91058 Erlangen, Germany
${ }^{\dagger}$ Universität Erlangen-Nürnberg, Institut für Organische Chemie II, Henkestrasse 42, 91054 Erlangen, Germany

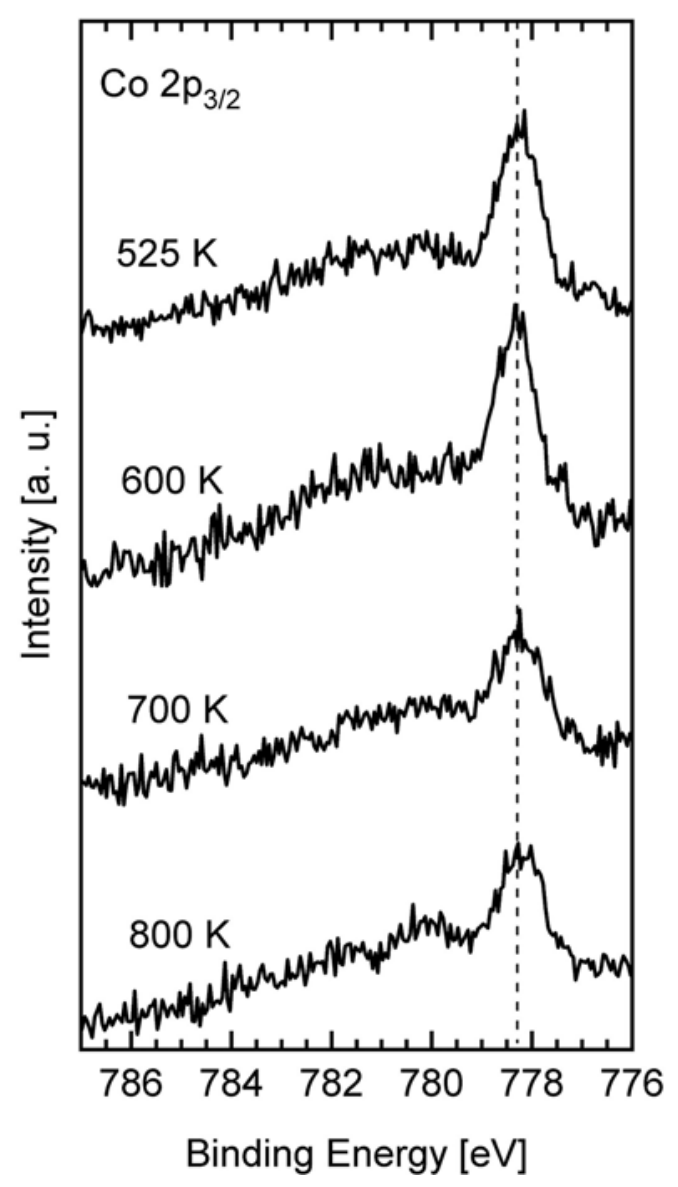

Figure S1: Co $2 \mathrm{p}_{3 / 2}$ XP spectra of CoTPP/Ag(111) at monolayer coverage $(\theta=0.037)$. The spectra were recorded at $300 \mathrm{~K}$ and in grazing emission $\left(80^{\circ}\right.$ relative to the surface normal) after heating to the indicated temperatures. 


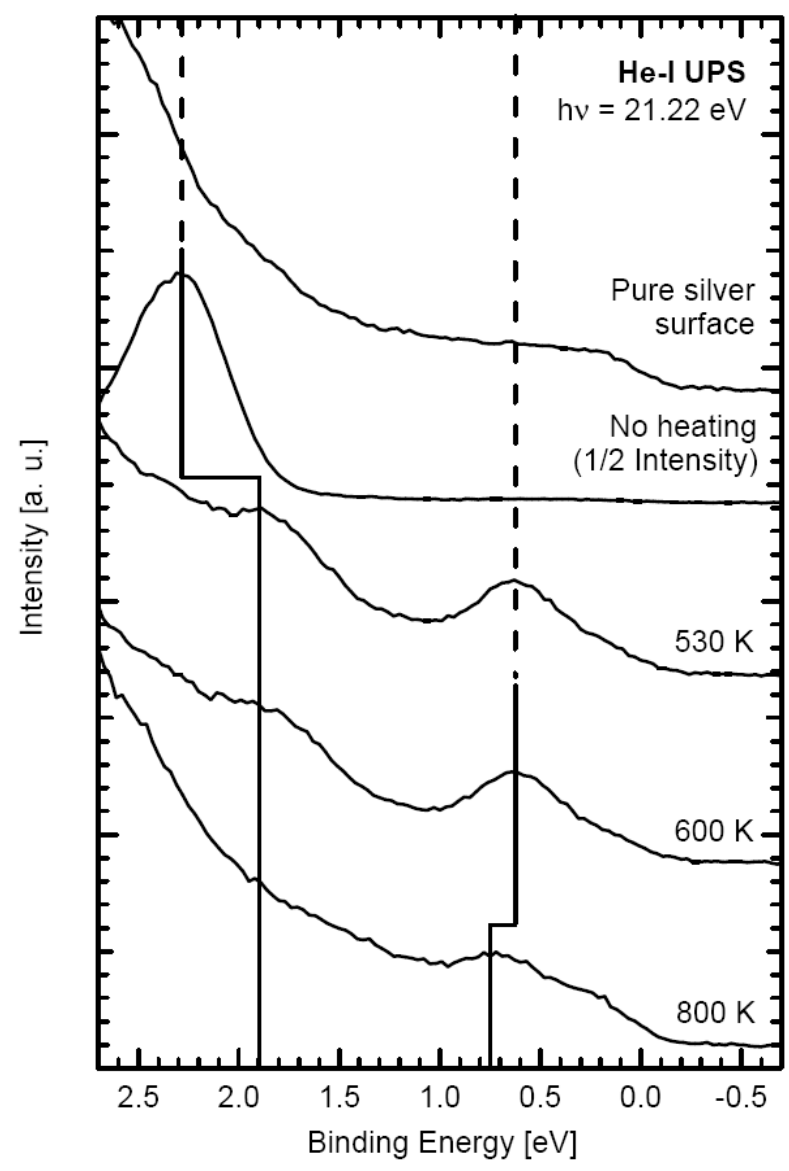

Figure S2: He-I UP spectra $(\mathrm{h} v=21.22 \mathrm{eV})$ of clean $\mathrm{Ag}(111)$, CoTPP multilayer (5 monolayers), CoTPP monolayer after heating to $530 \mathrm{~K}, 600 \mathrm{~K}$, and $800 \mathrm{~K}$ (from top to bottom). All spectra were taken in normal emission. 